\title{
Chapter 4 \\ Deconstructing and Embedding Cultural Competence in Initial Teacher Education: Responding to University Graduate Qualities for Undergraduate Students
}

\section{Sheelagh Daniels-Mayes}

\begin{abstract}
Graduate qualities, also known as graduate attributes, are a universalising and common feature in universities (Universities Australia, 2011). The intention is for graduate qualities to be addressed throughout an institution's curricula across all disciplines. Arguably, cultural competence is one of the most value-laden of all graduate qualities, having its origins in the fields of health, human services and education where various frameworks have been developed. The terms 'culture' and 'competence', which are derived from the concept, are complex ideas with no consensus on either term. This paper will focus specifically on the challenges of developing curricular that seeks to embed the graduate quality of 'cultural competence' into a first-year, mandatory Initial Teacher Education (ITE) Unit of Study with a large student cohort. The paper illustrates how the term 'cultural competence' was deconstructed using concept mapping and analysis by a team of diverse teacher educators. While an agreed-upon singular definition of cultural competence was not reached, all team members agreed that cultural competence is a social justice imperative in education. The intent of this paper is not to provide a formulaic, one-size-fits-all approach but rather reflect upon the multi-layered and complex nature of the task of building a future teacher workforce that is engaging in the continuous process of becoming culturally competent in an ever-increasing diverse world.
\end{abstract}

Keywords Aboriginal $\cdot$ Concept mapping $\cdot$ Cultural competence $\cdot$ Graduate qualities - Initial teacher education

\footnotetext{
S. Daniels-Mayes $(\bowtie)$

Sydney School of Education and Social Work, The University of Sydney, Sydney, NSW, Australia e-mail: sheelagh.daniels-mayes@sydney.edu.au
} 


\section{Introduction}

Graduate qualities, also known as graduate attributes, are a universalising and common feature in Australian universities (Universities Australia, 2011). The intention is for the graduate qualities to be addressed throughout the institution's curricula across all disciplines. The University of Sydney's 2016-20 Strategic Plan identifies the need to transform the undergraduate curriculum in order to produce graduates with the capacity to influence and contribute to changing and globalised environments (University of Sydney, 2016). The aim of the new curriculum framework is to balance depth of disciplinary expertise with broader capabilities. Nine graduate qualities were identified: depth of disciplinary expertise; critical thinking and problem solving; oral and written communication; information and digital literacy; inventiveness; cultural competence; interdisciplinary effectiveness; integrated professional, ethical and personal identity; and influence (https://sydney.edu.au/students/graduatequalities.html). One initiative offered by the strategy as a measure of success, states: 'Embed new graduate qualities and a new curriculum framework in all undergraduate qualities' (University of Sydney, 2016, p. 57). The Strategy further states:

5.1 Develop interactive and collaborative learning designs that foster excellence and innovation design experiences that promote the alignment of learning and assessment at multiple levels (task, unit, major, degree) and across disciplines.

5.2 Create contemporary environments that enable flexible and interactive learning (The University of Sydney, 2016, p. 38).

Arguably, cultural competence is one of the most value-laden of all graduate qualities. Cultural competence emerged from the fields of health, human services and education with various frameworks being developed using a diversity of definitions based on their respective disciplinary knowledges and worldviews. My aim in this paper is not to reproduce the extensive body of literature pertaining to cultural competence but rather to highlight the challenges we encountered in this project, starting with defining the term itself. Cross, Bazron, Dennis and Isaacs (1989, p. 189) provide one of the earliest definitions of cultural competence:

a set of congruent behaviours, attitudes, and policies that come together in a system, agency or among professionals and enable that system, or agency to work effectively in cross-cultural situations.

Used primarily within the health care field, Cross et al. (1989) advocate for cultural competence as a process that exists on a six-component continuum, with cultural destructiveness located at one end and cultural proficiency placed at the opposite end. Within this continuum, cultural competence is situated as the fifth component (Cross, et al., 1989); however, I agree with Davis (2007, p. 35) who argues:

One may say that even attempting to ascribe a static definition to cultural competence is antithetical to the fluid character fundamental to the concept because what is culturally competent to one may not reflect critical elements important to another. 
Perhaps then we need to look at the meaning of the two terms themselves: 'cultural' and 'competence'. First, 'cultural', a derivative of culture, is the adjectival component of the concept. Cross et al. (1989, p.7) define this problematic term as being,

the integrated pattern of human behaviour that includes thoughts, communications, actions, customs, beliefs, values, and institutions of a racial, ethnic, religious, or social group.

Second, 'competence' refers to performance that is sufficient and adequate, with synonyms for competence including capability, skill, fitness, aptitude and expertise (Rosenjack-Burchum, 2002, p. 6). Additionally, a variety of terms exist including cultural awareness, cultural sensitivity, cultural appropriateness, cultural competence, cultural responsiveness, cultural proficiency, cultural understanding, cultural integrity, cultural relevance, cultural humility and cultural safety. In short, the concept of cultural competency is dynamic, evolving and open to interpretation.

Despite the absence of a singularly agreed-upon definition or term, there is one significant theme strongly present in the literature. That is, cultural competence is a social justice project (Andersen, Bunda, \& Walter, 2008). With regards to the profession of teaching, Russo (2004) teaching for social justice has two key concepts. First, educators need to be able to recognise cycles of oppression where some groups of people are consistently privileged while others are consistently disadvantaged; the privileging and disadvantaging becomes unjust when it is unearned or undeserved. Second, educators need to become change agents able to interrupt cycles of oppression in their classrooms and the wider educational landscape. Teaching pre-service teachers to know how to disrupt (or challenge) oppression which means learning about (or creating) strategies to counter oppression (of 'race', class, gender, (dis)ability, sexuality and others) across the grade levels and content areas in which our teachers work. Teachers can work as change agents through the content or topics they address as well as through particular pedagogical practices that tend to undermine patterns of entrenched oppression (Russo, 2004). As will be expanded upon below, the imperative of graduating as culturally competent and socially-just teachers was common for all team members. This paper focuses on the processes undertaken to deconstruct the concept of cultural competence and how we embedded the identified components into the chosen course.

\section{Project Overview and Contextualisation}

Universities Australia (2011) in collaboration with the Indigenous Higher Education Advisory Council (IHEAC) provided the Australian higher education sector with a best practice framework outlining theoretical and practical tools to embed cultural competence at institutional levels. The objective was to provide encouraging and supportive environments for Indigenous students and staff, as well as to embed for non-Indigenous graduates the knowledge and skills necessary for them to provide genuinely competent services to the Australian Indigenous communities (Universities Australia, 2011, p. 6). In the Australian higher education context, it is considered 
that a culturally competent university would embrace the following values throughout their organisational fabric and extend cultural competence to every staff member and student. University Australia defines cultural competence in relation to the Australian higher education sector as:

Student and staff knowledge and understanding of Indigenous Australian cultures, histories and contemporary realities and awareness of Indigenous protocols, combined with the proficiency to engage and work effectively in Indigenous contexts congruent to the expectations of Indigenous Australian peoples (Universities Australia, 2011, p. 6).

Universities Australia (2011, p. 6) goes on to say:

Indigenous cultural competence requires an organisational culture which is committed to social justice, human rights and the process of reconciliation through valuing and supporting Indigenous cultures, knowledges and peoples as integral to the core business of the institution. It requires effective and inclusive policies and procedures, monitoring mechanisms and allocation of sufficient resources to foster culturally competent behaviour and practice at all levels of the institution.

Overall, University Australia argues that 'all graduates of Australian universities should be culturally competent' (2011, p. 9). More specifically, Recommendation 4 states: 'Train teaching staff in Indigenous pedagogy for teaching Indigenous Studies and students effectively, including developing appropriate content and learning resources, teaching strategies and assessment methods' (University Australia, 2011, p. 9).

Responding to this, funding was received in 2018 for a project named: Incorporating Cultural Competence in Faculty of Education \& Social Work Curriculum (Dr. Lynette Riley). This project, which became known as the 'Embeddedness Project', sought to address The University of Sydney's then new graduate quality: To work productively, collaboratively and openly in diverse groups and across cultural boundaries (University of Sydney, 2016, p. 35). The path chosen to achieve this outcome was to initially work with the first-year course coordinators, of the subject EDUF1018 Education, Teachers and Teaching (henceforth EDUF1018), which provides an introduction to key concepts in education including pedagogy, curriculum and assessment. This is a mandatory first-year course with a large student cohort of several hundred students in the School of Education and Social Work.

A literature review was undertaken prior to consultation with first-year coordinators that focused on understandings of cultural competence, terminologies used, its key components, frameworks and implementation across different fields and disciplines. Primarily literature from 2000 to the present was considered, though some historical scholarship was reviewed for contextualisation purposes. This revealed a considerable amount of scholarship. However, scant literature on the mechanisms for embedding and assessing cultural competence in university coursework was found. A Google Scholar search for "embed/ding cultural competence" university coursework, found only six hits (Fialho, 2013; Johnson, 2013, 2016; Pace \& Blue, 2016; Penn, 2011; Porterfield, 2016) with none of these being of significant help with the project. 
The project team consisted of nine teacher educators and a research assistant; members occupied a diversity of marginalised identities including differing cultures, genders, ages, (dis)abilities, and sexual orientations; members traversed the spectrum of early career academics to professorial standing; and while members crossed theoretical boundaries, generally speaking, as noted earlier, members would best be described as being committed to social justice and therefore take a critical stance in their work. As DiAngelo and Sensoy (2014, p. 1) poignantly writes:

By critical stance we mean those academic fields (including social justice, critical pedagogy, multicultural education, anti-racist, postcolonial, and feminist approaches) that operate from the perspective that knowledge is socially constructed, and that education is a political project embedded within a network of social institutions that reproduce inequality.

We recognised that when people (and in this case first year pre-service teachers) are confronted with evidence of inequality that challenges our identities, the response is often resistance in the form of '... silence, withdrawal, immobilising guilt, feeling overly hopeless or overly hopeful, rejection, anger, sarcasm, and argumentation' (DiAngelo \& Sensoy, 2014, p. 1). The often-mainstream narratives that inform our deeply held beliefs make studying and teaching from a critical stance very challenging. Therefore, team members knew that the task of teaching teachers to adopt a critical stance and engage in the process of becoming agents of change (Russo, 2004), is potentially one fraught with difficulty but nonetheless a social justice imperative in an ever-changing, increasingly diverse world. We understood too that graduating students who were all 'culturally competent' was idealistic, and instead aimed to graduate students who would strive to be culturally competent on an ongoing basis, potentially influencing systems, society, schools and education towards achieving social justice (Cross et al., 1989).

Team members met for two hours each week, for eight weeks, and then met as required as EDUF1018 curriculum and assessment was developed. Dropbox Professional was used to share gathered materials. All team members agreed that they did not like the term cultural competence and much discussion ensued. In the end it was decided that as all team members had some familiarity with the term, so cultural competence would be used as a default term (Bennett, Green, Gilbert, \& Bessarab, 2013), with the aim of the project being to deconstruct the concept into its relevant components as will now be discussed.

\section{Deconstructing Cultural Competence}

While the embeddedness project began with an Aboriginal focus, and kept this central, it evolved to include other categories of difference. Thus, 'cultural competence' came to include (but not limited to): culture, ethnicity, gender, ability, age and underserved communities with Aboriginality remaining central to discussion. This change recognised the multiple and intersecting cultural identities we all occupy. Key to the project was the development of conceptual definitions and teaching resources for 
explicitly embedding the cultural competence graduate quality in the unit of study for the mandatory subject of EDUF1018.

At the time of inheriting the leadership of this project from Dr Lynette Riley, I worked intuitively, inductively and responsively, drawing on my lived personal and professional experience as an Aboriginal woman living with disability. So, meetings one and two primarily consisted of information-gathering through discussion and brainstorming, gathering project team members' words and phrases to describe cultural competence and any questions or concerns held. This to me, and to team members, was a logical first phase; one that I had used extensively in my professional work as a project manager and researcher. A subsequent literature review revealed the methods of concept mapping (Davis, 2007) and concept analysis (Rodgers, 2000) which well described the approach I had undertaken to deconstruct the concept of cultural competence which I now briefly describe.

First, concept mapping (Davis, 2007) typically consists of six stages: (1) preparing for the project; (2) idea generation; (3) structuring ideas; (4) multivariate analyses; (5) interpretation; and (6) implementation. Second, Rodgers' (2000) concept analysis is understood as an evolutionary and inductive method of analysis, arguing that concepts develop over time and are influenced by the context in which they are used. The embeddedness project combined these two methods and resulted in three phases of the project as follows: (1) the initial phase, which included the collection of scholarship, gathering of team member knowledge and stances; (2) the core analysis and deconstruction and embeddedness process; and (3) the further analysis phase, in which questions for further analysis and work are identified. This project therefore implemented concept mapping and analysis in a way not previously applied to cultural competence and pre-service teacher education. What follows are the overall outcomes of the first two meetings of team members.

\section{Concept Mapping: Meeting One}

- Mind map on the whiteboard: priorities, concerns, questions, clarifications.

- No-one liked the term 'cultural competence' but agreed that it was a 'default' term, one that everyone had some familiarity with.

- Need to deconstruct the socially constructed concept of 'cultural competence': conceptual mapping terms.

- Need for future evaluation.

- Ensure the teaching/learning programs are strength based.

- Scaffold teaching and learning for students across all the course so as to decrease student resistance.

- Create consistent resources and definitions for teaching. 


\section{Concept Mapping: Meeting Two}

Building on Meeting One, team members brainstorm the themes and concepts implied in the term 'cultural competence' (Table 4.1).

Team members sorted generated concepts into conceptual groupings, placing for example, 'deficit and disadvantage', into one concept according to similarities and differences. This brought the deconstructed concepts down from forty-seven components to the twenty-one listed in Table 4.1. It was decided that each concept needed to be expanded upon with: (1) academic definition; (2) everyday definition that first-year students would readily understand; (3) any activities that could be used in lectures or seminars with students; and (4) articles and readings for both students and academics delivering the course. According to team members' knowledge, theoretical framework and lived experience, each member took 'ownership' of one or more concepts and were able to upload and share materials through Dropbox Professional. Each definition was presented to team members for discussion at subsequent meetings, and where need be, clarification was provided. At all times members were mindful of the student cohort to which we were teaching (i.e. first-year education students probably fresh out of high school). What follows (Table 4.2) is one example.

The team recognised that it was not practicable or reasonable for all twenty-one concepts to be included in EDUF1018. Students would, for example, require a scaffolded approach that would provide students with baseline knowledge that could then be built on as their education progressed. It needs to be noted too, that concepts did not necessarily explicitly appear in the unit of study but rather the components were embedded as initially intended. As critical theorists, who understand that knowledge is socially constructed and reinforced by mainstream narratives, we sought to provide a method for students to overcome their resistances and become agents of change in their classrooms and schools. To maximise student's learning of social justice content and subsequent action, our restructuring and course development was guided by the

Table 4.1 Deconstructing cultural competence

\begin{tabular}{|c|c|c|}
\hline \multicolumn{3}{|l|}{ Deconstructing cultural competence } \\
\hline Aboriginality & Equality and equity & Power and privilege \\
\hline Colonisation and dispossession & $\begin{array}{l}\text { Fundamentals (i.e. basic } \\
\text { knowledge students } \\
\text { should possess) }\end{array}$ & $\begin{array}{l}\text { Racism, 'race' and } \\
\text { racialisation }\end{array}$ \\
\hline $\begin{array}{l}\text { Cultural competence: } \\
\text { humility—responsiveness_-understanding }\end{array}$ & Inclusion and Exclusion & Reciprocity \\
\hline $\begin{array}{l}\text { Culturally responsive: } \\
\text { schools-teachers-pedagogies }\end{array}$ & $\begin{array}{l}\text { Intersectionality and } \\
\text { positionality }\end{array}$ & Social justice \\
\hline Culture and cultural & Kinship & Stereotyping \\
\hline Deficit and disadvantage & $\begin{array}{l}\text { Marginalisation and } \\
\text { minoritorisation }\end{array}$ & Subjectivity \\
\hline Discrimination & Microaggressions & Whiteness \\
\hline
\end{tabular}


Table 4.2 Microaggressions

\begin{tabular}{l|l}
\hline \multicolumn{1}{l|}{ Microaggressions } & $\begin{array}{l}\text { Microaggressions are the everyday verbal, nonverbal, and } \\
\text { environmental slights, snubs, or insults, whether intentional or } \\
\text { unintentional, that communicate hostile, derogatory, or } \\
\text { negative messages to target persons based solely upon their } \\
\text { marginalized group membership (from Diversity in the } \\
\text { Classroom, UCLA Diversity \& Faculty Development, 2014). } \\
\text { The first step in addressing microaggressions is to recognize } \\
\text { when a microaggression has occurred and what message it may } \\
\text { be sending. } \\
\text { Microaggression: brief, everyday exchanges that send } \\
\text { denigrating messages to certain individuals because of their } \\
\text { group membership (Wing, 2010). }\end{array}$ \\
\hline Resource & $\begin{array}{l}\text { Tool: Recognizing microaggressions and the messages they } \\
\text { send. Adapted from Wing, D. S. (2010). Microaggressions in } \\
\text { everyday life: Race, gender, and Sexual Orientation. New } \\
\text { Jersey: Wiley }\end{array}$ \\
\hline Reading & $\begin{array}{l}\text { Fricker (2007). Epistemic injustice: power and the ethics of } \\
\text { knowing. Oxford: Oxford University Press }\end{array}$ \\
\hline Critiques of Microaggression & $\begin{array}{l}\text { https://theconversation.com/the-trouble-with- } \\
\text { microaggressions-71364 } \\
\text { Fricker's (2007) work closely considers the injustice } \\
\text { perpetuated and felt by specific individual epistemic practices } \\
\text { (e.g., personal processes such as conveying knowledge to } \\
\text { others by speech and making meaning of social experiences) } \\
\text { within such social contexts. Fricker describes these epistemic } \\
\text { injustices as 'testimonial injustice, in which someone is } \\
\text { wronged in their capacity as a giver of knowledge; and } \\
\text { hermeneutical injustice, in which someone is wronged in their } \\
\text { capacity as a subject of social understanding' (page 7). }\end{array}$ \\
\hline
\end{tabular}

wisdom of DiAngelo and Sensoy's paper (2014, p. 3) Leaning in: A student's guide to engaging constructively with social justice content:

1. Strive for intellectual humility.

2. Recognise the difference between opinions and informed knowledge.

3. Let go of personal anecdotal evidence and look at broader societal patterns.

4. Notice your own defensive reactions and attempt to use these reactions as entry points for gaining deeper self-knowledge.

5. Recognise how your own social positionality (such as your 'race', class, gender, sexuality, ability-status) informs your perspectives and reactions to your instructor and those whose work you study in the course.

If our students could commence their journey down this intellectual and emotional path, then we believed we were on the right track for students to engage in a process of becoming 'culturally competent' teachers upon graduation, and to continue this 
developmental process beyond university striving for social justice by taking a critical stance (Cross et al., 1989; DiAngelo \& Sensoy, 2014).

\section{Implementation of Revised EDUF1018 Unit of Study}

In 2018, first-year pre-service students undertook the restructured and revised curriculum that sought to embed cultural competence into the unit of study course. During the twelve-week semester, more time was given to tutorials than to lectures (reduced to one per week in 2018 compared to two one-hour lectures in 2017). Lecture topics and readings reflected the deconstructed cultural competence terms as well as assessment tasks such as weekly self-reflection and groupwork.

\section{Conclusions and Future Directions}

The process undertaken in the Embeddedness Project needs to be evaluated. So far as we can ascertain from existing publications, EDUF 1018 Education, Teachers and Teaching is the first unit of study at the University of Sydney to attempt to embed and assess cultural competence content in response to the new graduate qualities. The first of these subjects EDUF1018 is the unit under restructure here. The key research question is: How might Cultural Competence content be embedded and assessed effectively whilst not being the core focus of a unit of work? Indeed, the answer to this question is more widely pressing as there seems to be scant scholarship on the mechanisms for embedding and assessing cultural competence in university coursework generally. In this sense, this research design is more exploratory, rather than confirmatory.

The consultation process in this project relied on teacher educators who possessed a diversity of knowledge and experience who take a critical stance in their teaching and research and are constantly striving to be culturally competent in the situations they find themselves. We believe we've conscientiously embedded the graduate quality cultural competence content in EDUF1018 coursework and assessment, but is this effective from a students' perspective and experience? Is the 'embedding' clear enough for student learning or does it need to be more explicit? If so, what content might that replace? Is there a case that first-year subjects like EDUF1018 are already overloaded with other embeddings such as first year transition and study skills concerns (see for example Gale \& Parker, 2014)? Are multiple embeddings overwhelming, distracting or helpful? We recognise that these are not questions that are answerable in the normal teaching and learning cycle or Unit of Study. In-depth exploratory, scholarly analysis of the teaching and learning in EDUF1018 is needed to come to better understand these intersections between embedding 'additional' course content, student learning and developing graduate qualities. While we have 
begun the process of evaluating the effectiveness of the project, the findings are still under analysis.

Acknowledgements The author acknowledges the project team members, pivotal in the Embeddedness Project: Lyn Riley, Tracey Cameron, Samantha McMahon, Matthew Thomas, Remy Low, Vic Rawlings, Alexandra McCormick, Valerie Harwood, Deb Hayes. Additionally, she acknowledges the input of: Belinda Chambers, James Tognolini, Arlene Harvey, Michelle Davidson, David Evans, Mareese Terare, and Jack Frawley, who have driven the Graduate Qualities measuring project of which she has been involved.

\section{References}

Andersen, C., Bunda, T., \& Walter, M. (2008). Indigenous higher education: The role of universities in releasing the potential. Australian Journal of Indigenous Education, 37, 1-8.

Bennett, B., Green, S., Gilbert, S., \& Bessarab, D. (2013). Our voices: Aboriginal and Torres Strait Islander social work. Melbourne: Palgrave Macmillan.

Cross, T., Bazron, B., Dennis, K., \& Isaacs, M. (1989). Towards a culturally competent system of care, vol. 1. Washington. DC: National Technical Assistance Center for Children's Mental Health, Georgetown University Child Development Center.

Davis, T. S. (2007). Mapping patterns of perceptions: A community-based approach to cultural competence assessment. Research on Social Work Practice, 17(3), 358-379.

DiAngelo, R., \& Sensoy, Ö. (2014). Leaning in: A student's guide to engaging constructively with social justice content. Radical Pedagogy, 11(1), (Article 2).

Fialho, M. (2013). Engage, Empower, enact: Evaluating a cultural competence program at UWA. Perth, WA: University of Western Australia.

Fricker, M. (2007). Epistemic injustice: Power and the ethics of knowing. Oxford: Oxford University Press.

Gale, T., \& Parker, S. (2014). Navigating change: A typology of student transition in higher education. Studies in Higher Education, 39(5), 734-753. https://doi.org/10.1080/03075079.2012. 721351.

Johnson, J. L. (2013) School psychology and cultural responsiveness: Re-forming identities. PhD Thesis: University of Missouri-St. Louis.

Johnson, T. M. (2016). Culturally responsive policy in an urban Head Start program. Doctoral Dissertations. National Louis University, Dissertation Paper 163.

Pace, D. A., \& Blue, E. V. (2016). Meeting the international need for special educators with online education. Journal of the International Association of Special Education, 1, 100-108.

Penn, C. (2011). Cultural safety and the curriculum: Recommendations for global practice. Perspectives on Global Issues in Communication Sciences and Related Disorders, 1, 4-11. https:// doi.org/10.1044/gics1.1.4.

Porterfield, M. L. (2016). Cultural competence in North Carolina's early care and education system. Master's Thesis. University of North Carolina, Greensboro.

Rodgers, B. L. (2000). Concept analysis: An evolutionary view. In B. L. Rodgers \& K. A. Knafl (Eds.), Concept development in nursing: Foundations, techniques, and applications (pp. 77-102). Philadelphia: Saunders.

Rosenjack-Burchum, J. L. (2002). Cultural competence: An evolutionary perspective. Nursing Forum, 37(4), 5-15.

Russo, P. (2004). What does it mean to teach for social justice? Retrieved from https://www.oswego. edu/ prusso1/Russos_what_does_it_mean_to_teach_for_s.htm. 
The University of Sydney. (2016). The University of Sydney 2016-20 Strategic Plan. Retrieved from https://sydney.edu.au/dam/intranet/documents/strategy-and-planning/strategic-plan-201620.pdf.

Universities Australia. (2011). National best practice framework for cultural competency in Australian Universities. Retrieved from http://www.indigenousculturalcompetency.edu.au/index. html.

Wing, D. S. (2010). Microaggressions in everyday life: Race, gender, and Sexual Orientation. New Jersey: Wiley, New Jersey.

Open Access This chapter is licensed under the terms of the Creative Commons Attribution 4.0 International License (http://creativecommons.org/licenses/by/4.0/), which permits use, sharing, adaptation, distribution and reproduction in any medium or format, as long as you give appropriate credit to the original author(s) and the source, provide a link to the Creative Commons license and indicate if changes were made.

The images or other third party material in this chapter are included in the chapter's Creative Commons license, unless indicated otherwise in a credit line to the material. If material is not included in the chapter's Creative Commons license and your intended use is not permitted by statutory regulation or exceeds the permitted use, you will need to obtain permission directly from the copyright holder. 